\title{
Industrialisierung des Controllings
}

Die Größe eines Wortes stellt die relative Häufigkeit in allen Beiträgen der Rubrik Schwerpunkt dar.

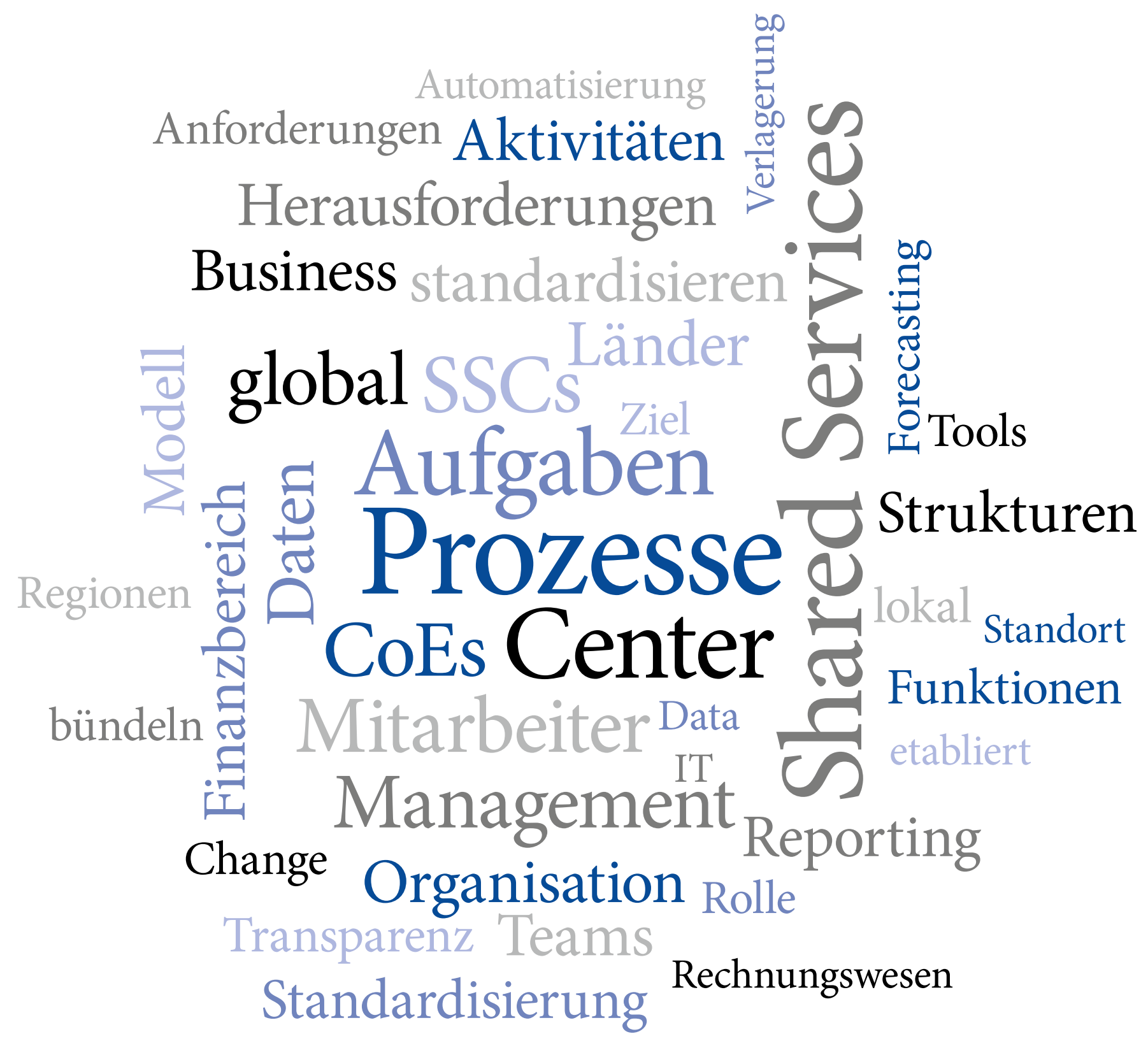

